\title{
PERENCANAAN INSTALASI PENGOLAHAN AIR LIMBAH (IPAL) DOMESTIK DENGAN METODE CONSTRUCTED WETLAND DI PERUMAHAN BUMI CIRUAS PERMAI 1 KABUPATEN SERANG
}

(diterima 1 Maret 2021, diperbaiki 1 April 2021, disetujui 1 Juni 2021)

\author{
Wilda Fajar Gusti Ayu, Frebhika Sri Puji Pangesti*
}

Program Studi Teknik Lingkungan, Fakultas Teknik, Universitas Banten Jaya

Jl.Ciwaru II No.73 Kota Serang - Banten

E-mail korespondensi*: frebhikasripujipangesti@unbaja.ac.id

\begin{abstract}
BCP 1 housing is one of the waste generators in the Ciruas District area. This housing does not yet have gray water and black water waste treatment facilities. Therefore, an appropriate and efficient gray water wastewater treatment system is needed. One alternative is to use the subsurface flow wetland method. This study aims to determine the volume of wastewater generated by the community of BCP 1 and to design a wastewater treatment plant. The WWTP planning in BCP 1 considers aspects of the quality of domestic wastewater generated every day. The quality of domestic wastewater shows a COD value of $19.8 \mathrm{mg} / \mathrm{L} ; \mathrm{BOD} 12.75 \mathrm{mg} / \mathrm{L} ; \mathrm{TSS} 84 \mathrm{mg} / \mathrm{L}$ and $\mathrm{pH}$ 7.6. Then an analysis of the calculation of each WWTP unit that will be planned in BCP 1 housing is carried out to match the quality standard criteria in accordance with Permen LHK P.68/MENLHK-SETJEN/2016. The WWTP system is planned to consist of an equalization tank unit, a Subsurface Flow Constructed Wetland with Cyperus alternifolius plants, and a holding pond. The planning results show that the processing efficiency for TSS is 88\%; BOD of $12.75 \mathrm{mg} / \mathrm{L}$; COD of $19.8 \mathrm{mg} / \mathrm{L} ; \mathrm{pH}$ of 7.6. The effluent of the WWTP has met the specified quality standards. The budget required for the construction of the WWTP is Rp. 588,191,894.
\end{abstract}

Keywords: Pollution; domestic waste; gray water; Cyperus alternifolius; Constructed Wetland.

Abstrak. Perumahan BCP 1 adalah salah satu penghasil limbah di wilayah Kecamatan Ciruas. Perumahan ini belum memiliki fasilitas pengolahan limbah grey water dan black water. Oleh karena itu, diperlukan sistem pengolahan air limbah grey water yang tepat dan efisien. Salah satu alternatifnya menggunakan metode subsurface flow wetland. Penelitian ini bertujuan untuk mengetahui volume air limbah yang dihasilkan oleh masyarakat Perumahan BCP 1 dan membuat desain pengolahan air limbah. Perencanaan IPAL di Perumahan BCP 1 mempertimbangkan aspek kualitas air limbah domestik yang dihasilkan setiap harinya. Kualitas air limbah domestik menunjukkan nilai COD 19,8 mg/L; BOD 12,75 mg/L; TSS $84 \mathrm{mg} / \mathrm{L}$ dan pH 7,6. Kemudian dilakukan analisis perhitungan masing- masing unit IPAL yang akan direncanakan di perumahan BCP 1 agar sesuai dengan kriteria baku mutu sesuai dengan Permen LHK P.68/MENLHK-SETJEN/2016. Sistem IPAL direncanakan terdiri dari unit bak ekualisasi, Subsurface Flow Constructed Wetland dengan tanaman Cyperus alternifolius, dan kolam penampungan. Hasil perencanaan menunjukkan efisiensi pengolahan untuk TSS sebesar 88\%; BOD sebesar 12,75 mg/L; COD sebesar 19,8 mg/L; pH sebesar 7,6. Dengan efisiensi tersebut effluent limbah cair IPAL telah memenuhi baku mutu yang ditentukan. Anggaran biaya yang dibutuhkan untuk pembangunan IPAL adalah Rp. 588.191.894.

Kata Kunci: Pencemaran; limbah domestic; grey water; Cyperus alternifolius; Constructed Wetland.

(C) hak cipta dilindungi undang-undang 


\section{PENDAHULUAN}

Pencemaran atau polusi merupakan perubahan karakteristik fisik, kimia, biologi yang mempengaruhi kehidupan manusia,kehidupan industri, kemajuan industri, kondisi kehidupan dan aset budaya (Mitra, 2018). Peningkatan jumlah penduduk terutama masalah pemukiman menyebabkan peningkatan buangan limbah karena tidak adanya sistem pengolahan, tetapi limbah yang langsung dialirkan ke badan air. Kondisi tersebut, pada satu sisi dapat memberikan kemudahan untuk penanggulangan maupun pengelolaan air limbah secara terpadu, namun disisi lain banyak teknologi pengolahan air limbah (IPAL) yang berjalan kurang efektif, karena mahalnya biaya operasional dan rumitnya sistem pengoperasian sehingga diperlukan sistem pengolahan air limbah (IPAL) domestik yang sederhana, mudah dan murah untuk biaya pembuatan dan operasionalnya.

Oleh karena itu, perlu dilakukan pengembangan teknologi constructed wetland yang dapat diterapkan pada halaman sempit. Teknologi constructed wetland dapat diterapkan sebagai teknologi pengolahan limbah grey water (domestik) di perumahan. Constructed wetland adalah lahan basah buatan, dengan fungsi pemurnian air limbah dengan menggunakan fisik, kimia dan metode biologi dalam sebuah ekosistem, memanfaatkan proses filtrasi, adsorpsi, sedimentasi, pertukaran ion dan penguraian mikroba (Torrens, 2015). Instalasi pengolahan ini mampu mengolah limbah domestik dengan baik ditunjukkan dengan efisiensi pengolahan limbah yang tinggi yaitu sekitar $88 \%$ untuk penurunan polutan TSS (Rito, 2017).

Penggunaan constructed wetland dengan tanaman Cyperus alternifolius dapat menjadi alternatif pengolahan air limbah grey water skala perumahan. Keuntungan yang diperoleh dari sistem ini adalah memperoleh nilai efisiensi yang tinggi dan memperoleh desain IPAL yang memiliki nilai estetika (Suprihatin, 2015). Pada penelitian ini peneliti menggunakan metode constructed wetland untuk menurunkan polutan limbah cair domestik dengan parameter yang akan diturunkan yaitu BOD, COD, TSS dan $\mathrm{pH}$. 


\section{METODE}

\section{Jenis Dan Sumber Data}

Jenis data yang digunakan adalah data primer dan sekunder. Data primer diperoleh melalui data hasil observasi lapangan sedangkan data sekunder merupakan penunjang data primer yang diperoleh dari studi pustaka/literatur atau jurnal mengenai penelitian sejenis. Studi literatur mengenai data kependudukan yang diperoleh dari BPS Kabupaten Serang. Perencanaan instalasi pengolahan air limbah domestik ini melakukan percobaan berupa objek yang direncanakan lalu kemudian mengumpulkan infomasi dan hasil pengujian berupa sampel air buangan sebagai data primer perancangan.

\section{Pengolahan Data}

Pengolahan serta analisis data yang digunakan dalam perencanaan pengolahan limbah ini menggunakan literatur yang telah didapat sesuai dengan permasalahan yang ada yaitu :

1. Menghitung kebutuhan air bersih

Untuk menghitung kebutuhan air bersih maka diperlukan data jumlah penduduk lalu dikalikan dengan standar kebutuhan air bersih per liter per orang per hari sebesar 144 liter/hari. (Dirjen Cipta Karya, 2006).

a. Kebutuhan air bersih domestik

$$
\mathrm{Q}_{\text {ave }}=\mathrm{P}_{\mathrm{n}} \times \mathrm{q}
$$

Dimana:

$\mathrm{Q}_{\mathrm{ave}}=$ Kebutuhan air bersih (liter/hari)

$\mathrm{P}_{\mathrm{n}} \quad=$ Jumlah penduduk pada tahun $\mathrm{n}$ (orang)

$\mathrm{q}=$ Kebutuhan air bersih (liter/orang/hari)

b. Kebutuhan air bersih non domestik

$$
\mathrm{Q}_{\text {fave }}=\mathrm{P}_{\mathrm{f}} \mathrm{x} \mathrm{Q} \times \text { Asumsi jumlah pemakai }
$$

Dimana:

$\mathrm{Q}_{\text {fave }}=$ Kebutuhan air bersih (liter/hari)

$\mathrm{P}_{\mathrm{f}} \quad=$ Fasilitas umum

Ap = Asumsi Pemakaian (orang/unit)

$\mathrm{Q} \quad=$ debit (liter/orang/hari)

c. Menghitung debit air limbah

Untuk menghitung debit air limbah diperlukan data berupa jumlah kebutuhan air bersih yang dikalikan dengan $80 \%$. 


$$
\mathrm{Q}_{\mathrm{d}}=\frac{80}{100} \times \sum \mathrm{Q}_{\mathrm{ave}}
$$

Dimana:

Qd = Debit air limbah (liter/hari)

$\sum$ Qave = Kebutuhan air bersih (liter/hati)

d. Dan menghitung desain IPAL yang direncanakan

$$
\mathrm{V}=\mathrm{Qd}_{\mathrm{d}} \mathrm{td}
$$

Dimana:

$\mathrm{V} \quad=$ Volume $\left(\mathrm{m}^{3}\right)$

Qd $\quad=$ Debit air limbah (liter/hari)

td $=$ Waktu tinggal

e. Perhitungan Unit Constructed Wetland

Menurut perhitungan waktu detensi di reaktor constructed wetland dengan pendekatan removal BOD/COD dan temperatur, dengan rumus sebagai berikut:

- Efisiensi pengolahan BOD

$$
\mathrm{R}_{\mathrm{BOD}}=\frac{\mathrm{C} \text { in }-\mathrm{C} \text { out }}{\mathrm{C} \text { in }}
$$

Dimana:

$\mathrm{R}_{\mathrm{BOD}}=$ Efisiensi pengolahan $\mathrm{BOD}$

$\mathrm{C}_{\mathrm{in}} \quad=$ Konsentrasi influent $(\mathrm{mg} / \mathrm{L})$

$\mathrm{C}_{\text {out }} \quad=$ Konsentrasi effluent $(\mathrm{mg} / \mathrm{L})$

- Waktu detensi pengolahan BOD

$$
\mathrm{R}_{\mathrm{BOD}}=\frac{\mathrm{HRT}}{\left(\frac{2,8}{\mathrm{~T}}\right)+\mathrm{HRT}}
$$

\section{Dimana:}

HRT = Hydraulic Residence Time (hari)

$\mathrm{T}=$ Temperature $\left({ }^{0} \mathrm{C}\right)$

- Efisiensi pengolahan COD

$$
\mathrm{R}_{\mathrm{COD}}=\frac{\mathrm{C} \text { in }-\mathrm{C} \text { out }}{\mathrm{C} \text { in }}
$$

Dimana:

$\mathrm{R}_{\mathrm{COD}}=$ Efisiensi pengolahan COD

$\mathrm{C}_{\mathrm{in}} \quad=$ Konsentrasi influent $(\mathrm{mg} / \mathrm{L})$

$\mathrm{C}_{\text {out }}=$ Konsentrasi effluent $(\mathrm{mg} / \mathrm{L})$

- Waktu detensi pengolahan COD

$$
\mathrm{R}_{\mathrm{COD}}=\frac{\mathrm{HRT}}{\left(\frac{15}{\mathrm{~T}}\right)+\mathrm{HRT}}
$$


Dimana:

HRT = Hydraulic Residence Time (hari)

$\mathrm{T} \quad=$ Temperature $\left({ }^{0} \mathrm{C}\right)$

\section{f. Perhitungan Evapotranspirasi dan Presipitasi}

Pada unit SSFCW terjadi reaksi evapotranspirasi yang mengakibatkan berkurangnya kuantitas air dalam unit ini.

$\underline{\text { Perhitungan Kehilangan Tekan }}$

- Perhitungan headloss pada pipa bertekanan dihitung menggunakan rumus Hazzen-William, dengan perhitungan sebagai berikut:

$$
\mathrm{hf}=\left[\frac{\mathrm{Q}}{0,2785 \cdot \mathrm{C} \cdot \mathrm{D}^{2,63}}\right]^{1,85} \mathrm{~L}
$$

Dimana:

$$
\begin{array}{ll}
\mathrm{hf} & =\text { headloss }(\mathrm{m}) \\
\mathrm{Q} & =\operatorname{debit}\left(\mathrm{m}^{3} / \mathrm{s}\right) \\
\mathrm{C} & =\text { koefisien kekasaran } \\
\mathrm{L} & =\text { panjang pipa }(\mathrm{m})
\end{array}
$$

- Headloss pada aksesoris dihitung menggunakan rumus Hazzen-William, dengan perhitungan sebagai berikut:

$$
\mathrm{hf}=\mathrm{n}\left[\frac{k V^{2}}{2 \mathrm{~g}}\right]
$$

Dimana:

$$
\begin{array}{ll}
\mathrm{hf} & =\text { headloss }(\mathrm{m}) \\
\mathrm{n} & =\text { jumlah aksesoris } \\
\mathrm{V} & =\text { kecepatan di dalam aksesoris }(\mathrm{m} / \mathrm{s}) \\
\mathrm{g} & =\text { percepatan gravitasi }\left(9,81 \mathrm{~m} / \mathrm{s}^{2}\right)
\end{array}
$$

Unit IPAL yang direncanakan berupa kolam ekualisasi, unit Constructed wetland, dan kolam penampungan. Kolam ekualisasi pada pengolahan berfungsi untuk menghomogenkan air limbah dan menjaga air limbah tidak berfluktuasi (Mubin, 2016). Perhitungan desain kolam ekualisasi sebagai berikut:

$$
\mathrm{V}=\frac{\mathrm{HRT}}{24} \times \mathrm{Q}
$$

Dimana:

$$
\begin{array}{ll}
\mathrm{V} & =\text { Volum bak ekualisasi }\left(\mathrm{m}^{3}\right) \\
\mathrm{HRT} & =\text { Hydraulic Retention Time }(\mathrm{jam}) \\
\mathrm{Q} & =\text { Debit air limbah }
\end{array}
$$

Dimensi unit constructed wetland dipengaruhi oleh faktor utama yaitu seberapa besar efisiensi pengolahan yang diinginkan (Nurul, 2016). Efisiensi dipengaruhi oleh faktor utama yaitu waktu tinggal hidraulik (HRT) seberapa lama air limbah berada pada 
unit constructed wetland. Permodelan perhitungan waktu detensi di reaktor constructed wetland dengan pendekatan removal TSS, persamaan rumus sebagai berikut [8]:

Efisiensi pengolahan TSS

$$
\mathrm{R}_{\mathrm{TSS}}=\frac{\mathrm{Co}-\mathrm{Cin}}{\mathrm{Co}} \times 100 \%
$$

Dimana:

$\mathrm{R}_{\mathrm{TSS}}=$ Efisiensi pengolahan TSS

$\mathrm{C}_{\mathrm{in}} \quad=$ Konsentrasi influent $(\mathrm{mg} / \mathrm{L})$

$\mathrm{C}_{\text {out }}=$ Konsentrasi effluent $(\mathrm{mg} / \mathrm{L})$

\section{Teknik Pengumpulan Data}

Pengumpulan data dalam perencanaan adalah data primer dan data sekunder. Data Primer berupa karakteristik limbah meliputi BOD, COD, TSS, dan pH. Pengambilan sampel air sebanyak 2 kali dengan 2 titik pengambilan secara grab sample pada pagi hari. Dilakukan pengukuran luas lahan area IPAL. Untuk data sekunder yang dibutuhkan adalah denah area Perumahan Bumi Ciruas Permai 1, baku mutu air limbah berdasarkan Peraturan Menteri Lingkungan Hidup dan Kehutanan Republik Indonesia P.68/MENLHK- SETJEN/2016.

\section{HASIL DAN PEMBAHASAN}

\section{Kualitas Air Limbah Domestik}

Hasil dari karakteristik air limbah dibandingkan dengan Baku Mutu Air Limbah Domestik sesuai dengan Peraturan Menteri Lingkungan Hidup dan Kehutanan Republik Indonesia P.68/MENLHK-SETJEN/2016. Hasil karakteristik air limbah pada Tabel 1 sebagai berikut:

Tabel 1. Karakteristik Air Limbah

\begin{tabular}{cccccc}
\hline Parameter & Satuan & \multicolumn{2}{c}{ Nilai } & Rata-Rata & Baku Mutu \\
\hline BOD & $\mathrm{mg} / \mathrm{L}$ & 15,3 & 10,2 & 12,75 & 30 \\
COD & $\mathrm{mg} / \mathrm{L}$ & 20,9 & 18,7 & 19,8 & 100 \\
TSS & $\mathrm{mg} / \mathrm{L}$ & 113,5 & 54,5 & 84 & 30 \\
pH & & 7,54 & 7,73 & 7,6 & $6-9$ \\
\hline
\end{tabular}

Sumber: Hasil Uji Laboratorium 2020

Berdasarkan hasil analisa di atas, data yang digunakan untuk perencanaan sebagai berikut: TSS $=84 \mathrm{mg} / \mathrm{L} ; \mathrm{COD}=19,8 \mathrm{mg} / \mathrm{L}$ dan $\mathrm{BOD}=12,75 \mathrm{mg} / \mathrm{L}$ 


\section{Kuantitas Air Limbah}

Kuantitas air limbah domestik didasarkan dari data jumlah penduduk masyarakat Perumahan Bumi Ciruas Permai 1 yang dikalikan dengan standar kebutuhan air bersih per liter per orang per hari sebesar 144 liter/hari (Widiana dan Wardana, 2012). Hasil dari pengumpulan data kuantitas air bersih didapatkan total kebutuhan air bersih sebesar 316.546 liter/hari. Pada perencanaan diterapkan 80\% merupakan angka persentase untuk menentukan air limbah dari penggunaan air bersih masyarakat Perumahan Bumi Ciruas Permai 1. Hal ini disesuaikan dengan literatur bahwa debit air limbah dapat diperkirakan mencapai $80 \%$ kebutuhan air bersih pada perumahan (Safrodin, et.al., 2017). Untuk limbah grey water diperkirakan 50-80\% dari total air limbah perumahan. Oleh karena itu dalam perencanaan diterapkan $75 \%$ limbah grey water dari total air limbah domestik. Di peroleh total debit air limbah grey water masyarakat Perumahan Bumi Ciruas Permai 1 sebagai berikut:

$$
\begin{aligned}
Q \text { grey water } & =\mathrm{Q} \text { limbah total } \times 75 \% \\
& =253,237 \mathrm{~m}^{3} / \text { hari } \times 75 \% \\
& =189,92 \mathrm{~m}^{3} / \text { hari }
\end{aligned}
$$

\section{Kesetimbangan Massa}

Penentuan kesetimbangan massa diperlukan untuk menentukan arah massa yang terbebaskan akibat proses pengolahan air limbah grey water dalam IPAL Subsurface Flow Constructed Wetland (Tutlomondo, et.al., 2015). Adanya kesetimbangan massa juga berfungsi untuk menentukan sistem operasi dan pemeliharaan IPAL. Mass balance IPAL Subsurface Flow Constructed Wetland dapat dilihat pada Gambar 1.

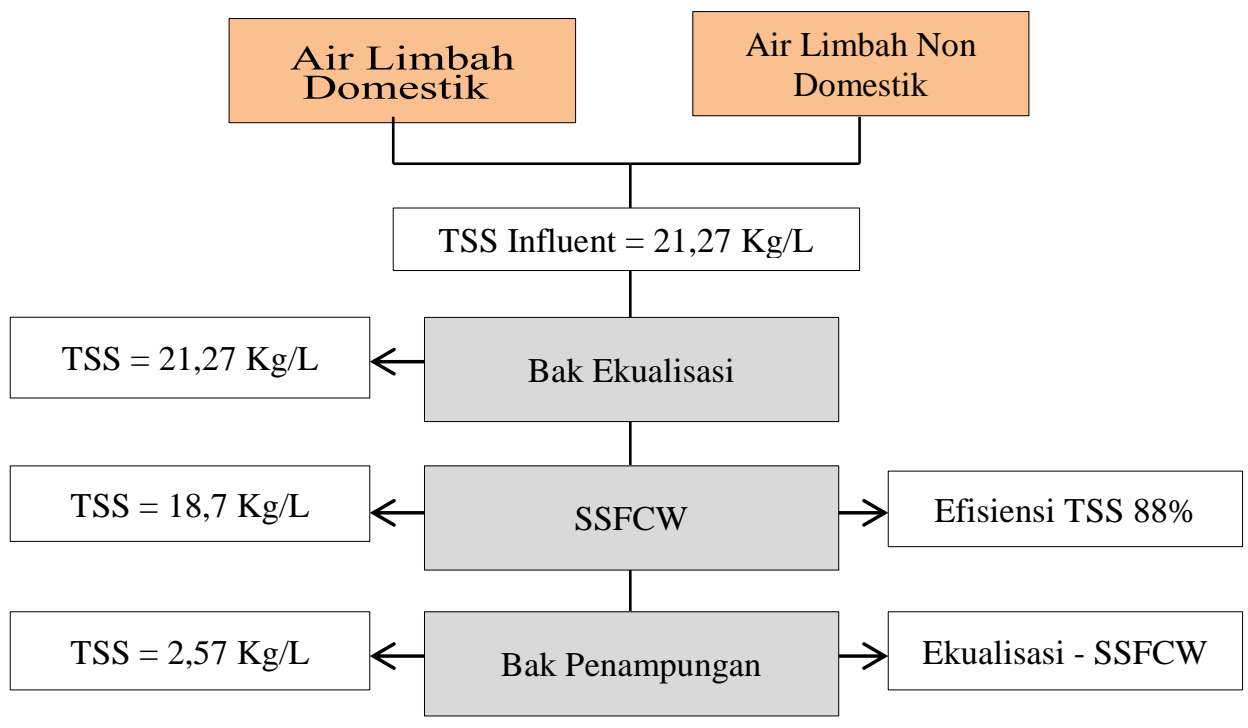

Gambar 1 Massa Balance Polutan dalam Sistem IPAL 
Sedangkan kesetimbangan massa air akibat pengaruh presipitasi dan evapotranspirasi ditampilkan pada Gambar 2.

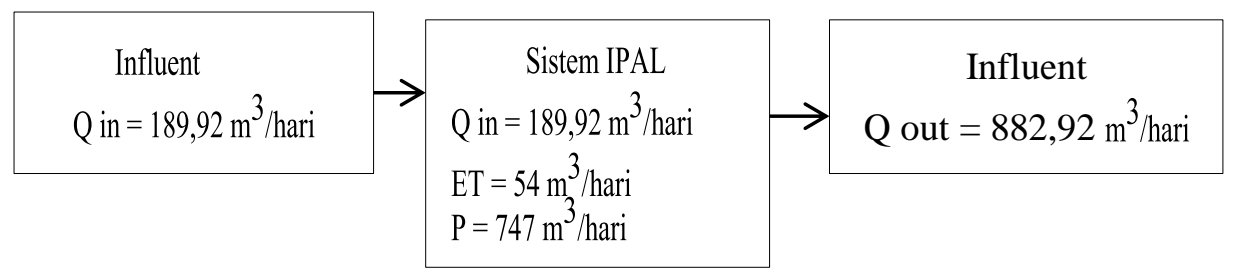

Gambar 2 Kesetimbangan Massa Air

Berdasarkan diagram alir water balance diatas dijelaskan bahwa nilai Evapotranspirasi didapatkan dari hasil penelitian dengan Cyperus alternifolius disesuaikan dengan temperatur Kabupaten Serang sekitar $27,4{ }^{\circ} \mathrm{C}$.

$$
\begin{aligned}
\left(\text { ET }_{\text {CYP }}\right) & =\frac{24 \mathrm{~mm}}{\text { hari }} \times \frac{1 \mathrm{~mm}}{1000} \times 2250 \mathrm{~m}^{2} \\
& =54 \mathrm{~m}^{3} / \text { hari } \\
\text { (P) } & =\frac{332 \mathrm{~mm}}{\text { hari }} \times \frac{1 \mathrm{~mm}}{1000} \times 2250 \mathrm{~m}^{2} \\
& =747 \mathrm{~m}^{3} / \text { hari }
\end{aligned}
$$

\section{Perencanaan Unit-Unit Pengolah Air Limbah}

Perencanaan IPAL terdiri atas bak ekualisasi, bangunan Subsurface Flow Constructed Wetland, dan bak penampung.

\section{a. Bak Ekualisasi}

Bak ekualisasi difungsikan sebagai bak penampung awal untuk menjaga kuantitas debit air limbah yang masuk. Debit atau aliran dan konsentrasi limbah yang fluktuatif akan disamakan debit dan konsentrasinya dalam bak ekualisasi, sehingga memberikan kondisi optimum pada pengolahan selanjutnya. Unit ini direncanakan berbentuk persegi panjang dan pengaliran dari bak ekualisasi ke unit berikutnya (SSFCW) dengan pemompaan agar beban air limbah merata. Dimensi Bak Ekualisasi Direncanakan:

$$
\begin{aligned}
\text { Volume Bak Ekualisasi } & =\frac{\mathrm{HRT}}{24} \times \mathrm{Q} \\
& =\frac{2 \mathrm{jam}}{24 \mathrm{jam}} \times 189,92 \mathrm{~m}^{3} / \text { hari } \\
& =16 \mathrm{~m}^{3}
\end{aligned}
$$

Dimensi bak ekualisasi:

$\begin{array}{ll}\text { Volume } & =16 \mathrm{~m}^{3} \\ \mathrm{H} & =2 \mathrm{~m} \\ \text { Luas } & =8 \mathrm{~m}^{2}\end{array}$




$\begin{array}{ll}\mathrm{Fb} & =0,3 \mathrm{~m} \\ \text { Panjang } & =4 \mathrm{~m} \\ \text { Lebar } & =2 \mathrm{~m}\end{array}$

Desain unit kolam Ekualisasi dapat dilihat pada gambar 3

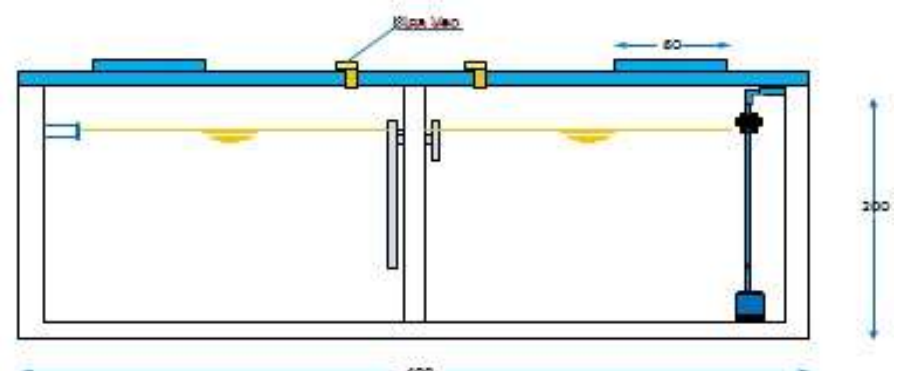

Gambar 3 Bak Ekualisasi

\section{b. Reaktor Constructed Wetland}

Subsurface Flow Constructed Wetland (SSFCW) direncanakan berbentuk persegi panjang dan terbagi atas beberapa kompartmen. Pembagian kompartmen bertujuan untuk meratakan persebaran air dan memudahkan dalam perawatan unit SSFCW. Waktu detensi (HRT) di unit SSFCW selama 3 hari. Tanaman yang digunakan pada unit adalah Cyperus alternifolius dengan kerapatan penanaman dalam $1 \mathrm{~m}^{2}$ terdapat 1 rumpun (10-20 stems). Media yang digunakan pada unit ini terdiri dari Medium sand yang digunakan sebagai media melekatnya akar yang tercelup air limbah dan media gravel sebagai penyangga dibagian inlet dan outlet.

\begin{tabular}{|c|c|}
\hline \multicolumn{2}{|c|}{ Dimensi bak SSFCW: } \\
\hline Panjang & \\
\hline Lebar & $=90 \mathrm{~m}$ \\
\hline $\mathrm{H}$ & $=0,5 \mathrm{~m}$ \\
\hline $\mathrm{Td}$ & $=3$ hari \\
\hline Volume & $=1356 \mathrm{~m}^{3}$ \\
\hline As & $=2250 \mathrm{~m}^{2}$ \\
\hline HLR & $=0,08 \mathrm{~m}^{3} / \mathrm{m}^{2} \cdot$ hari \\
\hline $\mathrm{BOD}_{\mathrm{LR}}$ & $=1,076 \mathrm{gr} / \mathrm{m}^{2} \cdot$ hari \\
\hline
\end{tabular}

Desain unit reaktor SSFCWS dapat dilihat pada gambar 4 dan 5.

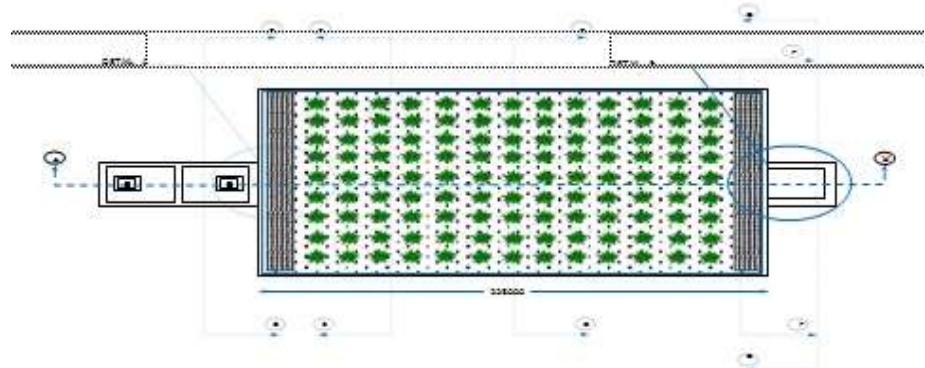

Gambar 4. Denah IPAL SSFCWS 


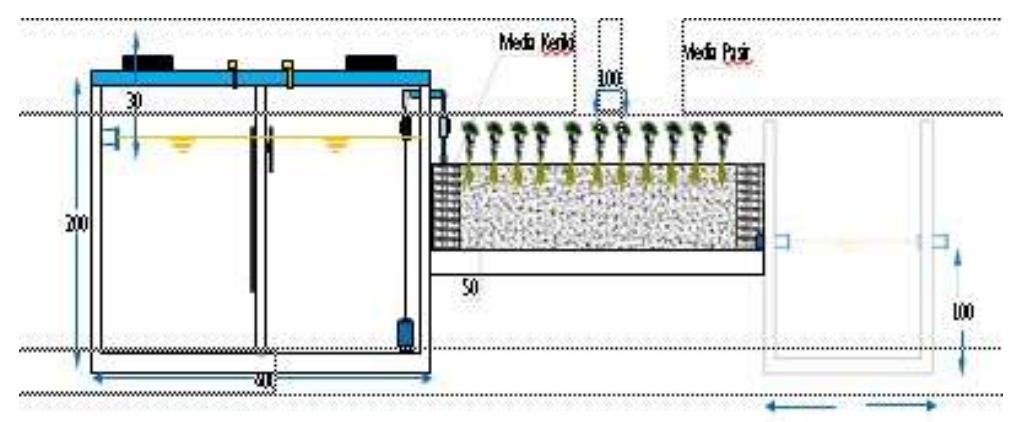

Gambar 5. Potongan SSFCWS

\section{c. Kolam Penampung}

Kolam penampung direncanakan untuk menampung air hasil olahan dari Subsurface Flow Constructed Wetland sebelum dibuang kebadan air. Kolam penampung dapat mempermudah proses operasi dan pemeliharaan khususnya pada proses pengambilan sampel efluent air limbah untuk diuji kensentrasinya disesuaikan dengan baku mutu yang ada. Fungsi lain dari kolam penampung adalah hasil pengolahan ini dapat juga dimanfaatkan kembali untuk air siram tanaman.

Dimensi bak penampungan:

$\begin{array}{ll}\text { Volume } & =23,74 \mathrm{~m}^{2} \\ \text { As } & =23,74 \mathrm{~m}^{2} \\ \text { Panjang } & =5 \mathrm{~m} \\ \text { Lebar } & =5 \mathrm{~m} \\ \mathrm{H} & =1 \mathrm{~m}\end{array}$

Desain unit reaktor SSFCWS dapat dilihat pada gambar 6.

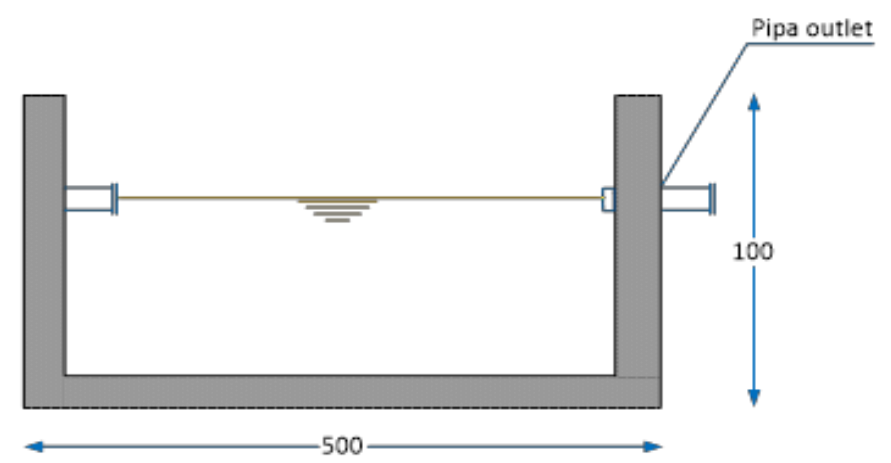

Gambar 6. Bak Penampungan

\section{Rencana Anggaran Biaya (RAB)}

Biaya yang dibutuhkan untuk mewujudkan unit IPAL Constructed Wetland sebesar Rp. 588.191.894. Hasil perhitungan RAB ditampilkan dalam Tabel 2. 
Tabel 2. Rencana Anggaran Biaya IPAL Constructed Wetland

\begin{tabular}{|c|c|c|}
\hline No & Uraian Pekerjaan & Harga \\
\hline 1 & Pembersihan Lapangan dan Penataan Tanaman & Rp 26.917 \\
\hline 2 & Pekerjaan penggalian tanah & Rp 74.568 \\
\hline 3 & Pekerjaan Pengurugan Pasir dengan Pemadatan & Rp 12.616.287 \\
\hline 4 & Pekerjaan beton & $\mathrm{Rp} 145.815 .441$ \\
\hline 5 & Pekerjaan Pembesian dengan Besi Beton (Polos/Ulir) & Kp L.Uชช.U33 \\
\hline 6 & Pekerjaan Bekisting Dinding & Rp 28.634.143 \\
\hline 7 & Pekerjaan Bekisting Lantai & $\operatorname{Rp} 28.864 .874$ \\
\hline 8 & Pekerjaan Pondasi Beton Bertulang & Rp 175.845 .418 \\
\hline 9 & Pekerjaan Pengurugan Tanah Kembali & Rp 38.761 \\
\hline 10 & $\begin{array}{l}\text { Pekeriaan Pengurugan Pasir, Kerikil dan Tanaman } \\
\text { Pada SSFCW }\end{array}$ & $\operatorname{Rp} 184.966 .852$ \\
\hline \multirow[t]{2}{*}{11} & Pompa, Pipa dan Aksesorisnya & $\mathrm{Rp} 9.220 .600$ \\
\hline & Total Biaya & Rp 588.191.894 \\
\hline
\end{tabular}

\section{KESIMPULAN}

Dari studi perencanaan dan desain IPAL di Perumahan Bumi Ciruas Permai 1 ini dapat disimpulkan bahwa:

1. Volume air limbah domestik yang dihasilkan masyarakat Perumahan Bumi Ciruas Permai 1 untuk 10 tahun mendatang sebesar 253.237 liter/hari. IPAL dengan menggunakan metode Constructed Wetland mampu mereduksi polutan TSS sebesar $88 \%$ dari semula TSS sebesar $84 \mathrm{mg} / \mathrm{L}$ menjadi 9,63 mg/L. Hasil untuk parameter BOD sebesar 12,75 mg/L; COD sebesar 19,8 mg/L; pH sebesar 7,6 telah memenuhi standar baku mutu sesuai dengan Permen LHK P.68/MENLHK-SETJEN/2016.

2. Angggaran biaya yang dibutuhkan untuk mewujudkan unit IPAL adalah sebesar Rp 588.191.894,-

\section{DAFTAR PUSTAKA}

Mitra, A. (2016). Fundamentals of quality control and improvement. John Wiley \& Sons.

Torrens, A. (2015). Subsurface flow constructed wetlands for the treatment of wastewater from different sources. Design and operation (Doctoral dissertation, Universitat de Barcelona).

Rito, B. A. B. R. (2017). Pemanfaatan Constructed Wetland Sebagai Bagian Dari Rancangan Lansekap Ruang Publik Yang Berwawasan Ekologis Studi Kasus Houtan Park China. Jurnal Sains \& Teknologi Lingkungan, 9(1), 46-59. 
Suprihatin, H. (2014). Penurunan Konsentrasi BOD Limbah Domestik Menggunakan Sistem Wetland dengan Tanaman Hias Bintang Air (Cyperus alternifolius). Dinamika Lingkungan Indonesia, 1(2), 80-87.

Mubin, F., Binilang, A., \& Halim, F. (2016). Perencanaan sistem pengolahan air limbah domestik di Kelurahan Istiqlal Kota Manado. Jurnal Sipil Statik, 4(3).

Euis Nurul, H., \& Wahyu, A. (2010). Potensi dan pengaruh tanaman pada pengolahan air limbah domestik dengan sistem constructed wetland. Envirotek: Jurnal Ilmiah Teknik Lingkungan, 2(2), 11-18.

Widiana, S. (2013). Perencanaan Teknis Sistem Penyaluran dan Pengolahan Air Buangan Domestik (Studi Kasus: Kelurahan Bojongsalaman Kecamatan Semarang Barat Kota Semarang). Jurnal Teknik Lingkungan, 2(1), 1-9.

Safrodin, A., Mangkoedihardjo, S., \& Yuniarto, A. (2017). Desain IPAL Subsurface Flow Constructed Wetland Di Rusunawa Grudo Surabaya. IPTEK Journal of Proceedings Series, 3(5).

Tuttolomondo, T., Licata, M., Leto, C., Leone, R., \& La Bella, S. (2015). Effect of plant species on water balance in a pilot-scale horizontal subsurface flow constructed wetland planted with Arundo donax L. and Cyperus alternifolius L.-Two-year tests in a Mediterranean environment in the West of Sicily (Italy). Ecological Engineering, 74, 79-92.

Vymazal, J. (2010). Constructed wetlands for wastewater treatment. Water, 2(3), 530549. 